\title{
El inglés y el español desde una perspectiva cuantitativa y distributiva: equivalencias y contrastes $^{1}$
}

\author{
Pascual CANTOS \\ Aquilino SÁNCHEZ \\ Universidad de Murcia \\ pcantos@um.es \\ asanchez@um.es
}

Recibido: 7/01/2011

Aceptado: 21/03/2011

\begin{abstract}
RESUMEN
Las similitudes o diferencias que percibimos al comparar dos o más lenguas son siempre relativas. El análisis de estos contrastes lingüísticos se puede formalizar tanto desde diversos ángulos y/o niveles lingüísticos (fonético-fonológico, morfológico, sintáctico, semántico, pragmático, diacrónico, etc.), como mediante diferentes metodologías (inductiva, deductiva, descriptiva, etc.). La finalidad de este estudio comparativo entre el español y el inglés es ofrecer, por primera vez, datos cuantitativos objetivos y fiables sobre la estructura y vertebración del inventario léxico en ambas lenguas (riqueza léxica, crecimiento léxico: formas, tramos de frecuencias, formas léxicas y funcionales, formas más frecuentes, longitud de formas, etc.), y poder aproximarnos a las diferentes propiedades matemáticas que subyacen en las lenguas española e inglesa. Todos los datos cuantitativos se han obtenido partiendo de dos corpus lingüísticos equivalentes (en estructura, composición y tamaño: 20 millones de palabras): Cumbre (para el español) y Lacell (para el inglés).
\end{abstract}

Palabras clave: Propiedades cuantitativas, distribución del léxico, frecuencias, español, inglés.

\section{English and Spanish from a distributional and quantitative perspective: Equivalences and contrasts}

\begin{abstract}
The similarities or differences people perceive while comparing two or more languages are always relative. However, the analysis of these linguistic contrasts can be formalized either from different angles and/or linguistic levels (phonetic/phonological, morphological, syntactic, semantic, pragmatic, diachronic, etc.), or from different research methodologies (inductive, deductive, descriptive, etc.).

The purpose of this comparative study between Spanish and English is to offer, for the first time, objective and reliable quantitative data on the structure and structuring of the lexical inventory in both languages (lexical richness, lexical growth, types, frequency bands, lexical and functional types, most common types, type-length, etc.); and to approach the different underlying mathematical properties of
\end{abstract}

${ }^{1}$ Esta investigación deriva de otras afines relacionadas con el proyecto financiado por la Fundación SENECA, de la Comunidad Autónoma de la Región de Murcia, proyecto 00481/PI/04. 
Spanish and English. All the quantitative data were obtained from two equivalent linguistic corpora (in structure, composition and size: 20 million words): Cumbre (for Spanish) and Lacell (for English).

Keywords: Quantitative properties, lexical distribution, frequencies, Spanish, English

\section{INGLÉS Y ESPAÑOL: DOS LENGUAS DIFERENTES A PARTIR DE UN TRONCO COMÚN}

Para la mayor parte de los hablantes de inglés y de español, la percepción más generalizada es que ambas lenguas son muy diferentes. Las diferencias se suelen reducir a afirmaciones como 'el inglés es una lengua muy difícil de pronunciar', 'el español tiene muchas formas verbales', 'el inglés tiene una gramática más fácil que el español', 'el español tiene algunos sonidos muy difíciles, como la $z$, j', etc. ${ }^{2}$ Son afirmaciones muy genéricas, pero están basadas en la percepción que los hablantes de una de las dos lenguas tienen sobre la otra, especialmente cuando inician su aprendizaje. Para el lingüista, la gramática del inglés es tan complicada o compleja como la del español, si bien es cierto que en algunos aspectos, como el de las flexiones, el inglés ofrece un cuadro de formas más simplificado, debido al hecho de que no existe en esta lengua, por ejemplo, la flexión de género y, en consecuencia, disminuye también la cantidad de flexiones relativas al número, que sí está marcado en inglés. Por razones similares, el hablante inglés suele afirmar que el subjuntivo español, o las formas del pasado verbal, son muy difíciles, hecho evidente si se tiene en cuenta que el inglés ha desterrado prácticamente las formas del subjuntivo y ha simplificado notoriamente las de pasado. En realidad, la percepción de facilidad o dificultad de una lengua suele basarse en lo que podría denominarse 'su estructura superficial o formal', que es lo primero que el hablante percibe, dejando de lado aspectos quizás más fundamentales relativos a otros niveles de la lengua (el semántico, la organización de la oración o del discurso, etc.), menos perceptibles a primera vista.

La similitud o diferencia entre lenguas es siempre relativa. Si la comparación se estableciera entre el español y el chino, por ejemplo, las diferencias entre ambos idiomas serían muchas y profundas, ciertamente muchas más que las que separan el español y el inglés. Y si la comparación se llevara a cabo entre el español y el catalán, las coincidencias o semejanzas probablemente superarían a las diferencias.

Los lingüistas acostumbran a describir la historia de las lenguas utilizando el símil del árbol. La figura de un árbol refleja con fidelidad el desarrollo de las diferentes lenguas a partir de un tronco común, que luego se divide o subdivide en ramas, atendiendo al aislamiento o separación -y consiguiente diferenciación- de los grupos humanos que se valen de cada sistema lingüístico como medio de comunicación. El tronco común entre el inglés y el español se remonta al indo-indoeuropeo, lengua que

\footnotetext{
${ }^{2}$ Véase al respecto algunos foros de discusión, por ejemplo ¿Qué idioma crees que es más dificil de aprender: inglés o español? En http://es.answers.yahoo.com/question/index?qid=20090817200500AAZiP6H
} 
supuestamente predominaba en la zona poblada de Europa central y en una franja que se prolongaba desde los Balcanes hasta Irán, y que luego empezó a diferenciarse en varias lenguas y dialectos, en torno al tercer milenio antes de Cristo. El inglés y el español surgen de ramas y rutas diferentes: el inglés deriva de la rama germánica con importantes aportaciones posteriores del latín y del francés-, mientras que el español surge del latín, otra de las grandes divisiones en que se ramificó el indoeuropeo. El nacimiento y desarrollo de ambas lenguas no coincide plenamente en el tiempo, pero se lleva a cabo dentro de la relativa unidad geográfica y cultural de Europa. Este hecho -junto con otros- contribuye a la configuración de los dos idiomas 'limando' diferencias y acercando procedimientos y estructuras, como podrá comprobarse en los apartados siguientes.

\section{CUANTIFICACIÓN DE LOS HABLANTES DE INGLÉS Y ESPAÑOL}

El español y el inglés están prácticamente igualados en número de hablantes nativos, si bien es verdad que las estadísticas no coinciden plenamente, o bien porque los datos exactos son difíciles de computar, o bien porque los criterios de recopilación difieren en algunos parámetros. Globalmente, los datos sobre los hablantes de español e inglés como lengua materna pueden resumirse en la siguiente tabla (Tabla 1):

\begin{tabular}{|l|c|c|}
\hline & \multicolumn{2}{|c|}{ Estimación de The Ethnologue } \\
\hline Inglés (2008) & 328 Millones & $4,89 \%$ \\
\hline Español (2008) & 329 Millones & $4,90 \%$ \\
\hline Población mundial estimada (2008) & 6.706 Millones & $100,00 \%$ \\
\hline
\end{tabular}

Tabla 1. Hablantes nativos de español e inglés (2008) y porcentaje sobre población mundial

Los datos de hablantes nativos, tomados aisladamente, no bastarían sin embargo para dar una información ajustada sobre el uso de cada una de las dos lenguas. La lengua inglesa es actualmente lengua 'franca' en todo el mundo, y cuenta con ciertos privilegios en más de 75 países. Este hecho por sí solo hace que la cifra de hablantes de inglés como primera o segunda lengua supere con creces los mil millones de personas. The Internet World Stats ${ }^{5}$ eleva esta cifra a 1.247 millones (en 2008). Dentro de los mismos parámetros, el español alcanza los 408 millones. Si nos centramos en Europa, se calcula que la mitad de sus habitantes puede comunicarse en inglés, pero no en español. Algunos datos más son también significativos al respecto:

1. Una gran mayoría de científicos lee los textos de su especialidad en inglés.

2. Más del 75\% de la correspondencia en el mundo se lleva a cabo en inglés.

\footnotetext{
${ }^{3}$ En http://www.ethnologue.com

${ }^{4}$ En http://es.wikipedia.org/wiki/Poblacion_mundial

${ }^{5}$ En http://www.internetworldstats.com/languages.htm
} 
3. En cualquier momento del día, hay unos 120.000 alumnos estudiando inglés en centros del British Council desparramados por todo el mundo.

4. El número de alumnos que estudia inglés cada año asciende a más de mil millones.

5. Cada año viajan a Inglaterra más de 600.000 alumnos para estudiar inglés, generando unos ingresos de más de mil millones de libras anuales.

6. Más de un $80 \%$ de la información electrónica se almacena en inglés.

7. Y si nos centramos en Internet, los datos revelan de nuevo el incuestionable predominio del inglés como lengua vehicular, que copa casi un tercio de todos los usuarios (Tabla 2):

\begin{tabular}{|l|c|c|c|}
\hline & $\begin{array}{c}\text { Usuarios de } \\
\text { Internet }\end{array}$ & $\begin{array}{c}\text { Crecimiento en } \\
\text { Internet } \\
(2000-2008)\end{array}$ & $\begin{array}{c}\text { Usuarios de } \\
\text { Internet } \\
(\% \text { sobre el total })\end{array}$ \\
\hline Inglés & 463 Millones & $226,70 \%$ & $29,10 \%$ \\
\hline Español & 130 Millones & $619,30 \%$ & $8,20 \%$ \\
\hline Total mundial & 1.596 Millones & $342,20 \%$ & $100,00 \%$ \\
\hline
\end{tabular}

Tabla 2. El inglés y el español en Internet (Fuente: Internet World Stats ${ }^{6}, 2009$ )

Así pues, desde el punto de vista del número de hablantes nativos, ambas lenguas están equiparadas, pero en cuanto al uso de cada una de ellas en el contexto mundial, el inglés ocupa una preeminencia y liderazgo indiscutibles.

\section{EL LÉXICO INGLÉS Y ESPAÑOL}

\subsection{PALABRAS Y CONCEPTOS}

Uno de los aspectos que suelen llamar poderosamente la atención es la cuestión de cuántas son las palabras de que dispone una determinada lengua. De ahí que muchos hablantes se hagan la pregunta sobre 'cuál es la lengua más rica en palabras, la inglesa o la española'. El tema no es trivial, ya que si las palabras reflejan la conceptualización que los hablantes tienen de la realidad, en tal caso una mayor riqueza léxica equivaldría a una más rica conceptualización de aquella $\mathrm{y}$, en consecuencia, a una más rica y extensa capacidad comunicativa. Que una lengua disponga de más palabras que otra, significa que sus hablantes manejarán más conceptos.

En consecuencia, el tema de si una lengua cuenta con más o menos palabras respecto a otra u otras no es baladí. 'Ir de compras' implica una realidad subyacente y propia de una sociedad consumista, en la que abundan los productos y la gente dispone de dinero suficiente para a 'practicar' esa actividad. Difícilmente podríamos

\footnotetext{
${ }^{6}$ En http://www.internetworldstats.com
} 
imaginar esa actividad en una sociedad primitiva, o incluso en un país en el que el desarrollo económico no hubiera alcanzado ciertos mínimos. Y si no existe esa realidad, tampoco existe su conceptualización entre los hablantes de la comunidad. De manera similar, el término 'paella' no existe en muchas lenguas, sencillamente porque este plato tampoco existe en las sociedades que las hablan. Los conceptos, objetos o realidades dan origen a palabras para referirnos a ellos, y las palabras, a su vez, son reflejo de aquellos.

En razón de lo dicho, sería poco realista pretender definir con exactitud el número de palabras de una lengua: esto equivaldría a poder conocer con precisión el número de conceptos que los hablantes manejamos en la comunicación. Y no lo sería menos afirmar con ligereza que un idioma cuenta con más de un millón de palabras (el inglés), mientras otras (como el alemán, el francés o el español) cuentan sólo con cien o doscientas mil. ¿Podría darse tal diferencia en la conceptualización de la realidad en comunidades culturalmente tan afines como la inglesa, la alemana, la francesa o la española?

Además, el número exacto de palabras usadas en una lengua es imposible de determinar con precisión porque las lenguas están en continua evolución y no sería viable disponer de una lista completa y actualizada de todos los términos y conceptos relacionados y utilizados por los hablantes en cada momento. No obstante, es razonable atenerse a determinados criterios objetivos, en la medida en que tales criterios pueden ser tomados como representativos del uso que los hablantes hacen de una lengua. Hasta el presente, los diccionarios han sido aceptados y utilizados como instrumentos fiables respecto a los recursos léxicos de un idioma en cada momento histórico. Los recursos que actualmente ofrece Internet, así como la capacidad y velocidad de procesamiento que propician los ordenadores, mejoran la fiabilidad y precisión de las obras lexicográficas, pero aún no han dado origen a sustitutos fiables de las obras lexicográficas tradicionales. Para ello sería necesario recopilar fiablemente la producción lingüística dispersa en la red, sistematizarla, analizarla y definir los términos realmente utilizados y los sentidos atribuidos a cada uno de ellos. De momento, este objetivo aún debe ser alcanzado.

En cuanto a diccionarios, el Diccionario de la Real Academia de la Lengua Española (diccionario oficial de la lengua española) incluye unas 93.000 entradas en su última edición. El Gran Diccionario de Uso de la Lengua Española (SGEL, 2001), fundamentado en un corpus del español actual (Cumbre ${ }^{7}$ y más centrado en el uso real y actual del español, incluye poco más de 70.000. Así pues, podría afirmarse que el número de lemas de la lengua española, si nos atenemos a lo recogido en las fuentes lexicográficas, podría aproximarse, en el mejor de los casos, a los cien mil.

El inglés no cuenta con un ente oficial que regule el uso y registro de la lengua. Los intentos llevados a cabo por Jonathan Swift o su sucesor americano John Adams,

\footnotetext{
${ }^{7}$ Cumbre es un corpus de 20 millones de palabras, equilibrado en su diseño y referido al español oral y escrito usado en todos los países de habla hispana, entre 1950 y 1995. Cumbre es propiedad de la editorial SGEL S.A. y fue utilizado en la elaboración del Gran Diccionario de uso del español actual. Madrid: SGEL, 2001.
} 
en el siglo XVIII, no llegaron a buen fin y la Academia de la Lengua Inglesa nunca llegó a materializarse. Quizás este simple hecho ha propiciado el afán de los hablantes del inglés por cuantificar la riqueza léxica del idioma. McCrum et al. (1992), en su amena descripción de la historia de la lengua inglesa, afirman que esta lengua cuenta actualmente con el vocabulario más rico y extenso de todas las lenguas existentes (que suelen cifrarse en entre 3.000 y 6.000). Y en favor de tal afirmación aducen datos del Oxford English Dictionary, que contiene cerca de medio millón de palabras. A ellas hay que añadir las que no recoge esta obra, términos de carácter técnico y científico, dialectales, etc. Los autores no dudan en concluir que si se registraran todas las palabras existentes, se rondaría el millón de palabras. La Encyclopedia Americana (2006), de otra parte, afirma que el inglés ha pasado de las aproximadamente 50.000 palabras del inglés antiguo a las más de 650.000 de la actualidad. En términos aún más concretos, el Webster's Third New International Dictionary (2010), afirma que incluye más de 470.000 entradas. La segunda edición del Oxford English Dictionary (1989) contenía poco más de 200.000 palabras. Estos diccionarios buscan todos ellos, de alguna manera, la exhaustividad, meta ciertamente difícil de lograr. En conclusión, comparando los datos de las obras mencionadas, el inglés multiplicaría hasta por cinco el volumen léxico del español: 650.000 frente a menos de 100.000. ¿Puede ser tomado este dato como realista? Es decir, ¿cabe pensar que la comunidad de hablantes del inglés supere en cinco veces la capacidad expresiva de la comunidad de hablantes de español, o que su riqueza conceptual sea cinco veces mayor? Si esta conclusión es difícil de imaginar, las diferencias detectadas en las obras lexicográficas deben responder a otros factores. Uno de ellos podría ser la menor atención prestada al estudio del léxico en la comunidad de hispanohablantes. Este hecho explicaría que los diccionarios del español suelan reducirse a recopilar las palabras más habituales en la comunicación, incluso poniendo el énfasis en la producción literaria y humanística, pero dejando de lado, entre otros, el léxico técnico-científico, las novedades léxicas más recientes, o el vocabulario especializado, dialectal o regional. Y el segundo factor que merece una atención especial es la metodología usada en la elaboración de los diccionarios. Si se unificase el método (criterios y recursos) sobre el cual se asentase la preparación de las obras lexicográficas, los resultados obtenidos alcanzarían un grado de fiabilidad mucho más alto que el actual.

Lo apuntado en el párrafo anterior se ve corroborado por el análisis de algunas obras lexicográficas generales del inglés. En efecto, los diccionarios generales del inglés elaborados con criterios similares a los habituales entre la comunidad hispanohablante no se diferencian tanto de los diccionarios del español o de otras lenguas del entorno (como el francés o el alemán). The New Oxford Dictionary of English (NODE) (1998) recoge unas 90.000 entradas (según la proyección estadística de una muestra parcial de la obra). En la solapa, los autores mencionan la cifra de '350.000 voces, frases y definiciones', pero no deben confundirse las voces o lemas con las formas (palabras diferentes en su forma) o con los significados o acepciones de las voces registradas. 
Los datos léxicos incluidos en los diccionarios, aunque sean reales, deben ser analizados con atención para entenderlos en su justa medida. El número de voces seleccionadas puede variar:

1. Según el criterio que se aplique para definir lo que se entiende por 'palabra' en el diccionario;

2. Según los criterios seguidos para incluir o excluir determinados términos;

3. Según el tratamiento que se dé a los términos técnicos y especializados y a los nombres propios;

4. Según el criterio aplicado respecto al grado de exhaustividad que se pretende alcanzar. En la tradición lexicográfica inglesa y norteamericana se ha buscado con frecuencia la exhaustividad, sobre todo a partir del Oxford English Dictionary, finalizado en 1928, y a raíz de la 'guerra de los diccionarios' desatada en los Estados Unidos en la segunda mitad del s. XIX, en la que competían los diccionarios de Webster -más innovador- y de Worcester -más clásico y conservador. De ahí la tendencia en la lexicografía inglesa a incluir todo tipo de voces (derivados, nombres propios, voces coloquiales, obsoletas, slang, etc.).

Por otro lado, la propaganda de las obras lexicográficas se basa con excesiva frecuencia en la cantidad del caudal léxico incluido. Y en este aspecto, al lector se le confunde fácilmente apelando al número de voces, voces derivadas, voces compuestas, voces de igual forma y con más de una categoría gramatical, abreviaciones, nombres propios y número de significados, pero sin aclarar lo que cada cosa supone respecto al número de voces reales. El lector no versado tiende a asociar la cifra destacada con el número de palabras diferentes ofrecidas por el diccionario.

\subsection{CORPUS LINGÜÍSTICOS, FORMAS Y PALABRAS}

Los diccionarios suelen recoger el uso lingüístico actual y heredado. Es decir, son en gran medida sincrónicos y diacrónicos, y resultan de la conjunción de lo actual con lo heredado. Además, a lo heredado o transmitido por generaciones pasadas, se le suele atribuir más peso que a lo actual. Hay razones para que esto sea así (la estabilidad del sistema comunicativo, por ejemplo), pero hasta ahora contribuía a mantener esta situación una razón cualitativamente inocua: recopilar el uso lingüístico del presente con las herramientas de la lexicografía tradicional (ficha y lápiz, anotaciones ocasionales, obras literarias -sobre todo de autores ya consagrados) era una tarea difícil y poco eficiente. Desde finales del siglo XX, no obstante, la lexicografía cuenta ya con herramientas mucho más eficaces y fiables: los corpus lingüísticos, o grandes recopilaciones de muestras lingüísticas, orales y/o escritas, susceptibles de ser tomadas de cualquier ámbito comunicativo.

Los corpus adecuadamente diseñados reflejan con gran fidelidad cuál es el uso real de una lengua en el periodo en el cual se ha hecho la recopilación. Además, si el corpus es representativo del conjunto de un idioma, ofrecerá una radiografía fiel de cuáles y cuántas palabras 'están en activo' - se usan- en un determinado momento histórico. Los corpus Cumbre (del español contemporáneo) y Lacell (del inglés 
contemporáneo) creemos que responden a estas características y por esa razón serán tomados en este estudio como referencia para la proyección de datos comparativos relativos a la cantidad de palabras totales y palabras diferentes en las lenguas aquí comparadas. Es evidente que la estructura o características de un corpus condicionan de alguna manera la variedad de palabras contenidas en él. Es importante, por tanto, tener en cuenta que la proyección que hacemos a continuación debe tomarse como una proyección relativa, aplicable a textos o recopilaciones textuales de estructura y composición similar.

Nuestros corpus se ajustan a los siguientes parámetros:

1. Se refieren a la lengua española o inglesa de los últimos cincuenta años.

2. Recogen el habla de todos los países en los cuales tanto el español como el inglés son lenguas oficiales, aunque en cantidades notablemente sesgadas a favor de España y Reino Unido, con un porcentaje medio del $65 \%$ sobre el total, mientras que los países hispanoamericanos y los de habla inglesa diferentes del Reino Unido sólo cuentan con un $35 \%$ de las muestras.

3. Respecto a la modalidad de lengua, la lengua hablada recibe un $35 \%$ del peso total. A la lengua escrita se le asignó el $65 \%$. En ambas modalidades se buscó una amplia variedad respecto a los ámbitos de uso, tanto vertical como horizontalmente (la variedad de textos en su conjunto consta de varios miles de muestras diferentes).

4. Los listados de frecuencia fueron depurados de todos los elementos no estrictamente léxicos: se eliminaron, por ejemplo, todas las secuencias numéricas y de signos, aunque no las palabras con errores ortográficos o los términos extranjeros.

Los resultados obtenidos quedan reflejados en la Tabla 3:

\begin{tabular}{|l|c|c|c|}
\hline & Total de palabras & $\begin{array}{c}\text { Total de formas } \\
\text { (types) diferentes }\end{array}$ \\
\hline Inglés & $\begin{array}{c}\text { Corpus } \\
\text { (tokenserentes }\end{array}$ & 21.427 .248 & 173.391 \\
\hline Españonol & $\begin{array}{c}\text { Corpus } \\
\text { Cumbre }^{8}\end{array}$ & 21.785 .202 & 218.643 \\
\hline
\end{tabular}

Tabla 3. Corpus del inglés y del español: palabras (tokens) y formas diferentes (types)

Cabe destacar que el número de palabras diferentes está en relación directa con el tamaño del corpus, es decir, a mayor número de palabras (tokens) recopiladas corresponde mayor número de formas diferentes (types) $)^{9}$. Puede observarse en los datos de la Tabla 3 que el corpus Cumbre (español) y el corpus Lacell -de tamaño y estructura similares- presentan algunos rasgos diferenciadores en cuanto a la cantidad

\footnotetext{
${ }_{9}^{8}$ En http://www.um.es/grupos/grupo-lacell/quees.php

${ }^{9}$ No obstante, véase Sánchez y Cantos $(1997,1998)$ en relación con la naturaleza de la curva hiperbólica del incremento.
} 
de formas. Importa tener en cuenta que las palabras diferentes (types) no son necesariamente lemas. Además, los corpus suelen incluir un alto número de formas provenientes de otras lenguas, nombres propios, e incluso errores ortográficos que en cuanto 'diferentes' son contabilizados por el ordenador como formas distintas. Pero dado que la metodología aplicada en la recopilación es la misma para ambas lenguas, puede concluirse que los resultados son razonablemente válidos y homogéneos.

Los datos confirman algunas diferencias esperadas. El corpus español contiene 45.252 types más que su homólogo inglés. Lo cual hace que la relación type/token sea de 0,010 para el español, mientras para el inglés es de 0,008; o lo que es lo mismo, como media, en español la ratio de formas distintas es de aproximadamente 10 por cada 1.000 palabras de texto, mientras que en inglés esta cifra asciende solamente a 8 palabras. El español es por tanto más prolijo en formas que el inglés, conclusión ya previsible, dado que el español es una lengua con mayor carga flexiva.

Ratio_type_token Inglés $=\frac{\text { Types }}{\text { Tokens }}=\frac{173391}{21427428}=0,008$
Ratio_type_token ${ }_{\text {Español }}=\frac{\text { Types }}{\text { Tokens }}=\frac{218643}{21785302}=0,010$

De forma análoga, si se compara la repetición media de esas mismas formas en inglés y en español, los datos muestran diferencias significativas:

$$
\begin{aligned}
& R p_{-} \text {formas }_{\text {Inglés }}=\frac{21427428}{173391}=123,5786 \\
& R p_{-} \text {formas }_{\text {Español }}=\frac{21785302}{218643}=99,638
\end{aligned}
$$

La repetición media, por cada 21 millones de palabras, de una forma en inglés es de casi 124 veces, mientras que en español se llega sólo a 100. En consecuencia, en inglés las formas se repiten, como media, casi un $24 \%$ más que en español.

\subsection{EL RITMO INCREMENTAL DE LAS FORMAS}

Analicemos ahora las formas con mayor detalle. Para homogeneizar los resultados, es preciso determinar la relación entre palabras y formas mediante una medida estándar que nos permita establecer comparaciones directas entre ambas lenguas. Al tratarse de corpus con tamaños ligeramente divergentes, no utilizaremos la ratio entre las palabras (token) y las formas (types) ${ }^{10}$. En su lugar utilizaremos una fórmula para

\footnotetext{
${ }^{10}$ Medida conocida como ratio type-token.
} 
conocer la dependencia entre las palabras y las formas, independientemente del tamaño desigual de los corpus, como es la propuesta por Sánchez y Cantos (1997) ${ }^{11}$ :

$$
\text { Formas }=K \sqrt{\text { Palabras }}
$$

La medida $K$ determina el ritmo incremental de nuevas formas dentro de un texto. Esta medida $K$ es distinta para cada lengua, texto o autor, y actúa a modo de seña de identidad exclusiva, una especie de 'ADN'12 personal e intransferible. Así, para calcular la medida $K$ para el español e inglés bastará con transformar la fórmula original de Herdan en una expresión logarítmica, resultando:

$$
K=\frac{\text { Formas }}{\sqrt{\text { Palabras }}}
$$

Y obteniendo para el español el siguiente valor $K$ :

$$
K=\frac{218643}{\sqrt{21785302}}=\frac{218643}{4667,47}=46,84
$$

Y para el inglés:

$$
K=\frac{173391}{\sqrt{21427248}}=\frac{173391}{4628,95}=37,45
$$

Estos valores confirman que el ritmo incremental de formas del español es mayor que el del inglés. Además, estos valores nos permiten comparar ambas lenguas en cuanto a la relación que guardan entre palabras y formas, y hacen posible proyectar los datos y apreciar mejor el ritmo incremental de formas en español e inglés. En el Gráfico 1 se muestra el comportamiento y relación entre palabras y formas en español e inglés, proyectando los datos hasta 100 millones. Se aprecia cómo el español, por ser lengua más flexiva, contiene un repertorio de formas (types) más amplio que el inglés (ver también Tabla 4). El español cuenta con unas 21.000 formas de media más en un volumen de texto de 5 millones de palabras, cantidad que llega hasta casi 94.000 en 100 millones.

${ }^{11}$ Otros métodos alternativos son la ratio estandarizada type-token (Scott 1999), o los métodos propuestos por Tuldava (1995); Yang, Cantos y Song (2000); Chipere, Malvern, Richards y Duran (2001), entre otros.

${ }^{12}$ En Cantos (2000) se emplea este índice para la discriminación automática de textos dependiendo de la temática de los mismos. 


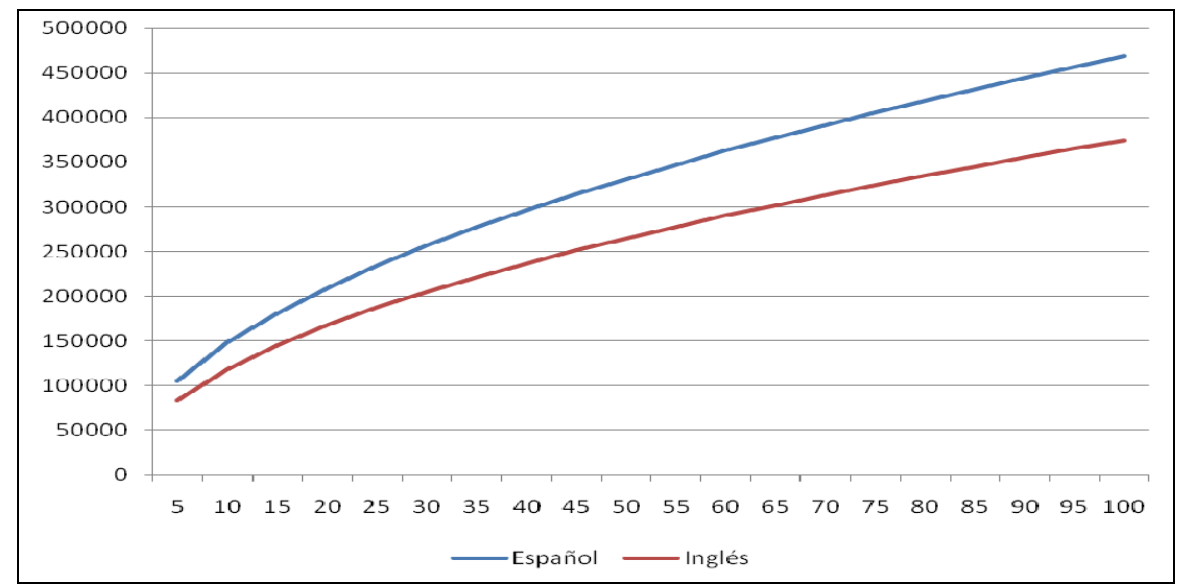

Gráfico 1. Ritmo incremental de formas en español e inglés

\begin{tabular}{|c|c|c|c|c|}
\hline \multirow[b]{2}{*}{ Palabras } & \multicolumn{4}{|c|}{ Formas } \\
\hline & Español & Inglés & Diferencia (E-I) & $\begin{array}{c}\text { Incremento } \\
\text { de la } \\
\text { diferencia (E- } \\
\text { I) }\end{array}$ \\
\hline 5000000 & 104737 & 83741 & 20997 & 20997 \\
\hline 10000000 & 148121 & 118427 & 29694 & 8697 \\
\hline 15000000 & 181411 & 145043 & 36367 & 6674 \\
\hline 20000000 & 209475 & 167481 & 41993 & 5626 \\
\hline 25000000 & 234200 & 187250 & 46950 & 4957 \\
\hline 30000000 & 256553 & 205122 & 51431 & 4481 \\
\hline 35000000 & 277109 & 221557 & 55552 & 4121 \\
\hline 40000000 & 296242 & 236855 & 59388 & 3836 \\
\hline 45000000 & 314212 & 251222 & 62990 & 3602 \\
\hline 50000000 & 331209 & 264811 & 66397 & 3407 \\
\hline 55000000 & 347375 & 277737 & 69638 & 3241 \\
\hline 60000000 & 362821 & 290086 & 72735 & 3097 \\
\hline 65000000 & 377636 & 301932 & 75705 & 2970 \\
\hline 70000000 & 391892 & 313329 & 78562 & 2858 \\
\hline 75000000 & 405646 & 324327 & 81320 & 2757 \\
\hline 80000000 & 418950 & 334963 & 83987 & 2667 \\
\hline 85000000 & 431843 & 345272 & 86572 & 2585 \\
\hline 90000000 & 444363 & 355282 & 89081 & 2510 \\
\hline 95000000 & 456540 & 365017 & 91522 & 2441 \\
\hline 100000000 & 468400 & 374500 & 93900 & 2378 \\
\hline
\end{tabular}

Tabla 4. Ritmo incremental de las formas en español e inglés 
Es interesante observar que el aumento de formas no es lineal, sino de tipo polinómico, lo que justifica que dicho ritmo vaya decreciendo poco a poco. Esta realidad es lógica, ya que cuanto más volumen de texto tenemos, más improbable resulta encontrar formas nuevas (las formas ya han aparecido previamente a lo largo de los textos precedentes).

Este mismo fenómeno -aumento no lineal, sino polinómico de las formas- explica también cómo la diferencia incremental de formas en español es superior al inglés y sigue a su vez un patrón exponencial (Gráfico 2).

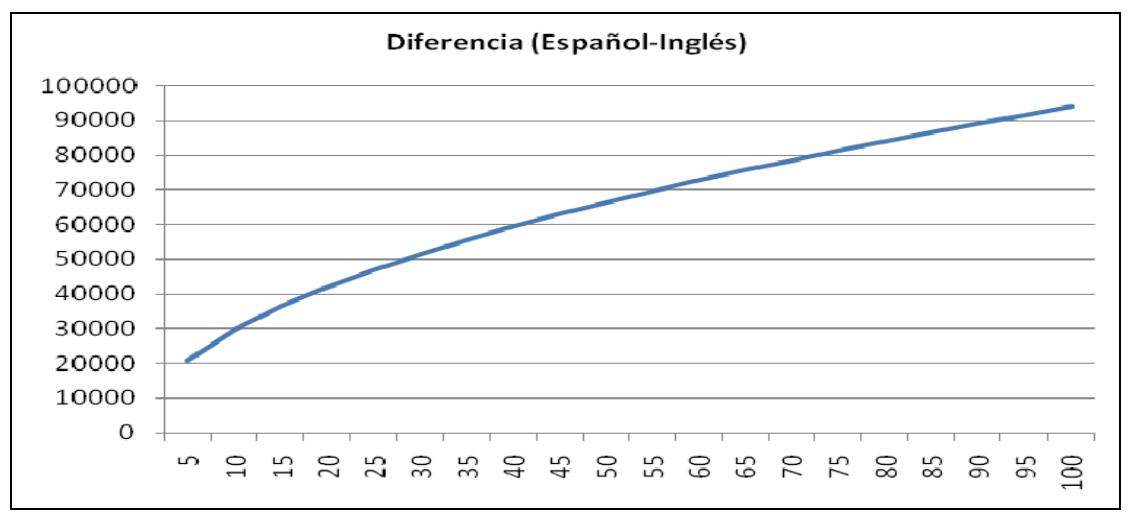

Gráfico 2. Diferencia del ritmo incremental de formas entre el español y el inglés

En consecuencia, es posible modelar el incremento de formas para el español y el inglés tomando como base las medidas $K$ para ambas lenguas, 46,84 y 37,45 respectivamente. Así para calcular el hipotético volumen de formas de un corpus español de 1.000 millones de formas, aplicaremos la siguiente fórmula:

Formas $=K \sqrt{\text { Palabras }}$

Asumiendo que $K=46,84$ y Palabras $=1.000 .000 .000$, se concluye que un corpus español de 1.000 millones de palabras contendría un volumen de 1.481.210 formas:

Formas $=46,84 \sqrt{1000000000}$

Formas $=46,84 * 31622,77$

Formas $=1481210,5468$

Y un corpus de inglés de idéntica magnitud, llegaría a 1.184.272 formas, 296.938 menos que un corpus español de igual tamaño.

Formas $=37,45 \sqrt{1000000000}$

Formas $=37,45 * 31622,77$

Formas $=1184272,73$ 
Llevando la hipótesis a cantidades extremas, un corpus del español de 1 trillón ${ }^{13}$ de palabras y otro de 1 trillón +1 millón de palabras (es decir, un millón de palabras más que el anterior) contendrían la misma cantidad de formas diferentes (types). Es decir, no se incrementarían las formas nuevas, puesto que todas ellas estarían ya contenidas en el corpus. Habríamos llegado a un punto de inflexión en el que no valdría la pena añadir más muestras textuales, puesto que tendríamos recogida prácticamente 'toda la lengua'.

Llegados a este punto, es importante advertir que la proyección de datos a 1.000 millones de palabras ha sido hecha tomando como referencias las medidas $K$ obtenidas a partir de los cálculos de los corpus Cumbre y Lacell para 21 millones de palabras. Lo cual significa que las proyecciones son únicamente válidas si los corpus de 1.000 millones de palabras a los cuales hemos hecho referencia mantienen la misma estructura y proporción en cuanto al contenido (textos de España e Hispanoamérica, -o del Reino Unido y demás países de habla inglesa)-, o porcentajes similares en las muestras orales y escritas, temática, etc. La proyección de datos de cualquier otro corpus del español y/o del inglés, con temáticas y estructuras distintas a las de Cumbre y Lacell, requeriría calcular previamente las constantes $K$ en cada caso, constantes que podrían variar, incluso de forma sustancial, con respecto a los obtenidos para los corpus Cumbre y Lacell.

\subsection{MÁS DATOS DISTRIBUTIVOS DEL ESPAÑOL Y DEL INGLÉS}

La frecuencia del léxico es variada. ¿Lo es también su distribución atendiendo a criterios de grupos o bandas de frecuencia? Es decir, ¿Tienen una distribución homogénea las palabras muy raras o muy poco frecuentes, las palabras de frecuencia baja media, etc.? Y esa distribución, ¿es similar en inglés y en español? La Tabla 5 ofrece datos clarificadores sobre la distribución de las palabras en tramos de frecuencia (según los corpus Cumbre y Lacell), tanto en español como en inglés:

\begin{tabular}{|l|c|c|c|c|}
\hline \multirow{2}{*}{ Tramos de frecuencias } & \multicolumn{3}{|c|}{ Frecuencia total por tramos y porcentajes } \\
\cline { 2 - 5 } & \multicolumn{2}{|c|}{ Español } & \multicolumn{2}{c|}{ Inglés } \\
\hline 1 & 85.350 & $39,04 \%$ & 60.231 & $34,74 \%$ \\
\hline $2-5$ & 53.331 & $24,39 \%$ & 45.052 & $25,98 \%$ \\
\hline $6-20$ & 44.046 & $20,15 \%$ & 35.088 & $20,24 \%$ \\
\hline $21-100$ & 23.200 & $10,61 \%$ & 20.699 & $11,94 \%$ \\
\hline $101-1000$ & 10.940 & $5,00 \%$ & 10.040 & $5,79 \%$ \\
\hline $1001-$ & 1.776 & $0,81 \%$ & 2.281 & $1,32 \%$ \\
\hline
\end{tabular}

Tabla 5. Frecuencias léxicas y su distribución, según el Corpus Cumbre y Lacell

Según estos datos, el español cuenta, en términos absolutos, con casi 25.000 palabras más que el inglés usadas solamente una vez; lo que corresponde a un $5 \%$

${ }^{13}$ Un millón de billones, o lo que es lo mismo, un uno seguido de 18 ceros. 
más de hápax legomena, una vez normalizados los datos para su mejor contraste. En los restantes tramos de frecuencia, las diferencias son menores (frecuencia de 6-20, por ejemplo; Gráfico 3).

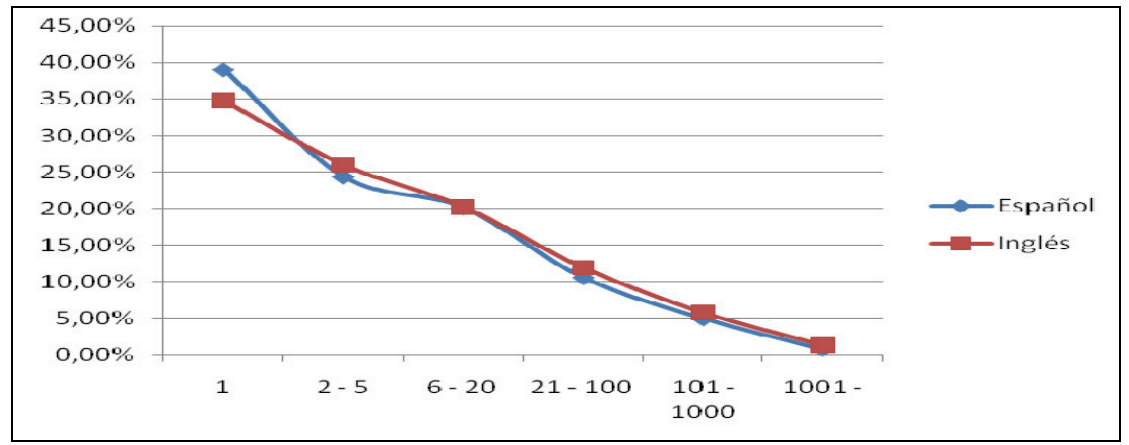

Gráfico 3. Frecuencias léxicas y su distribución en español e inglés

Si bien el número de formas (types) es mayor en español que en inglés, probablemente en razón de la mayor carga flexiva de aquel, el número de lemas no tiene por qué ajustarse exactamente al mismo parámetro, si bien tampoco cabe esperar desviaciones de importancia. Es difícil precisar el número de voces de una y otra lengua para aseverar sin reservas que una u otra cuenta con un acervo léxico más prolijo que la otra. Lo que sí cabe afirmar sin duda alguna es que el español es más flexivo que el inglés, especialmente en lo que respecta a las formas verbales y adjetivas. Ello hace que el español cuente con un inventario de formas (no necesariamente lemas) más elevado que el inglés. Al no disponer de ambos corpus lematizados, no es posible determinar con exactitud el número de lemas de cada corpus. Sí cabe identificar, no obstante, la cantidad de palabras léxicas y funcionales. La Tabla 6 muestra los datos de los corpus Cumbre y Lacell, referidos a los tres parámetros especificados:

\begin{tabular}{|c|c|c|c|}
\hline & Palabras & Palabras léxicas & $\begin{array}{c}\text { Palabras } \\
\text { funcionales }\end{array}$ \\
\hline CUMBRE (español) & 21.785 .302 & 16.916 .177 & 4.869 .125 \\
\hline LACELL (inglés) & 21.427 .248 & 18.053 .547 & 3.373 .701 \\
\hline
\end{tabular}

Tabla 6. Datos léxicos de los Cumbre y Lacell

Los datos reflejan que el uso de palabras léxicas (sustantivos, verbos, adjetivos y adverbios) es más frecuente entre angloparlantes que entre hispanohablantes. Los cálculos que siguen detallan las diferencias:

Palabras_léxicas $_{\text {Inglés }}=\frac{18 \cdot 053.547}{21.427 .248}=0,8425$ 
Palabras_léxicas $_{\text {Español }}=\frac{16.916 .177}{21.785 .302}=0,7764$

Mientras los primeros se valen, de media, de 84 palabras léxicas por cada cien palabras, los segundos reducen esta cifra a 78. Este hecho revela, en contrapartida, que el español abunda más que el inglés en el uso de palabras funcionales (preposiciones, artículos, pronombres, etc.).

Palabras_funcionales $_{\text {Inglés }}=\frac{3.373 .701}{21.427 .248}=0,1574$
Palabras_funcionales $_{\text {Español }}=\frac{4.869 .125}{21.785 .302}=0,2235$

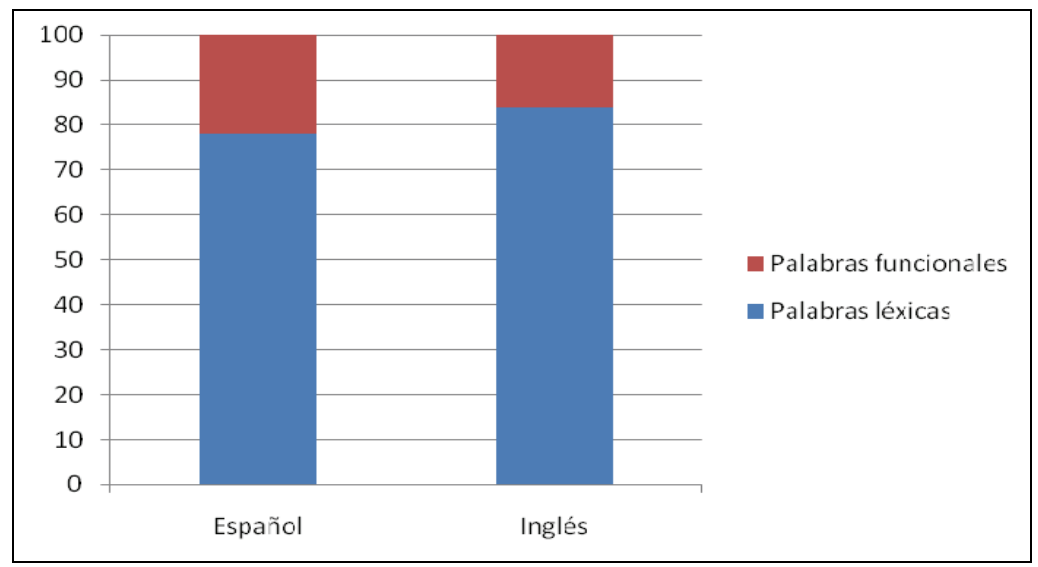

Gráfico 4. Distribución de palabras léxicas y funcionales en español e inglés

Se suele afirmar que el inglés es una lengua más sobria y concisa, menos proclive a la ornamentación léxica. Un reflejo de este supuesto podría detectarse en el número de oraciones usadas en cada lengua y en su longitud, asumiendo que frases más cortas implican el uso de menos recursos sintácticos y léxicos, y tienden a la concisión expresiva. El análisis de los dos corpus equivalentes, Cumbre y Lacell, demuestra en efecto, que las oraciones del español son, de media, más largas que las del inglés. Los datos de ambos corpus muestran que el corpus inglés contiene más frases (1.138.760) que el corpus español (1.042.417). La media de palabras por oración es consecuencia de estas cifras:

Ratio_palabras / oración $_{\text {Inglés }}=\frac{21.427 .248}{1.138 .760}=18,8162$

Ratio_palabras / oración $n_{\text {Español }}=\frac{21.785 \cdot 302}{1.042 .417}=20,8988$ 
A raíz de tales datos, podemos definir cómo sería un texto tipo de 1.000 palabras en inglés y en español:

1. En inglés constaría de 53 oraciones (con 19 palabras por oración); 843 palabras léxicas; 157 palabras funcionales.

2. En español constaría de 48 oraciones (21 palabras por oración); 776 palabras léxicas; 224 palabras funcionales.

Gráficamente, una oración tipo para el inglés y español se ajustaría al siguiente esquema gráfico ${ }^{14}$ :

\begin{tabular}{|c|c|c|c|c|c|c|c|c|c|c|c|c|c|c|c|c|c|c|c|c|}
\hline & & & & & & & & & & & & & & \\
\hline & & & & & & & & & & & & & & & & & & & & \\
\hline \multirow[t]{2}{*}{1} & 2 & 3 & 4 & 5 & 6 & 7 & 8 & 9 & 1 & 1 & 1 & 1 & 1 & 1 & 1 & 1 & 1 & 1 & & \\
\hline & & & & & & & & & 0 & 1 & 2 & 3 & 4 & 5 & 6 & 7 & 8 & 9 & & \\
\hline \multicolumn{21}{|c|}{ Inglés } \\
\hline & & & & & & & & & & & & & & & & & & & & \\
\hline \multirow[t]{2}{*}{1} & 2 & 3 & 4 & 5 & 6 & 7 & 8 & 9 & 1 & 1 & 1 & 1 & 1 & 1 & 1 & 1 & 1 & 1 & 2 & 2 \\
\hline & & & & & & & & & 0 & 1 & 2 & 3 & 4 & 5 & 6 & 7 & 8 & 9 & 0 & 1 \\
\hline \multicolumn{21}{|c|}{ Español } \\
\hline & & & & & & & & & & & & & & & & & & & & \\
\hline
\end{tabular}

Gráfico 5. Oración tipo: español versus inglés

Es frecuente hacer referencia a otro tópico en torno a la longitud de las palabras: las palabras en inglés -se dice- son más cortas que en español. De ahí -se arguye- la tendencia 'monosilábica' de la lengua anglosajona, menos perceptible en español debido a la mayor extensión de las palabras. El cómputo de las palabras de 1 a 10 caracteres en ambas lenguas confirma la tendencia del inglés hacia la 'concisión ortográfica'. Los datos globales son los siguientes (Tabla 7):

\begin{tabular}{|c|c|c|}
\hline & Español & Inglés \\
\hline $\begin{array}{c}\text { Media de letras por } \\
\text { palabra }\end{array}$ & 4,423 & 3,992 \\
\hline
\end{tabular}

Tabla 7. Letras por palabras

La media general en la longitud de las palabras no presenta discrepancias de relieve entre ambos idiomas. Pero el contraste del número de palabras con igual cantidad de letras sí es bastante más significativo en algunos casos. Destacan especialmente (i) las palabras de una sola letra, que son más de tres veces superiores en número en inglés que en español (aunque no debe olvidarse la escasa importancia de este tipo de palabras en inglés: se reducen al artículo 'a' -con casi medio millón de

\footnotetext{
${ }^{14}$ Cada celda equivale a una palabra.
} 
casos- y a las letras del alfabeto usadas para abrir párrafos o similares); (ii) las palabras de dos letras, cuyo número en inglés supera al del español en casi dos millones; o (iii) las palabras de 4 letras, que en inglés casi duplican el volumen del español. La Tabla 8 y el Gráfico 6 recogen los datos referidos a palabras de 1 a 10 letras en cada idioma:

\begin{tabular}{|c|c|c|c|c|}
\hline \multirow{2}{*}{ Letras por palabra } & \multicolumn{2}{|c|}{ Español } & \multicolumn{2}{c|}{ Inglés } \\
\cline { 2 - 5 } & Frecuencias & $\%$ & Frecuencias & $\%$ \\
\hline 1 letra & 816.275 & 3,75 & 2.656 .653 & 12,40 \\
\hline 2 letras & 3.642 .015 & 16,72 & 5.335 .686 & 24,90 \\
\hline 3 letras & 4.366 .524 & 20,04 & 3.335 .324 & 15,57 \\
\hline 4 letras & 3.637 .621 & 16,70 & 1.939 .735 & 9,05 \\
\hline 5 letras & 2.408 .555 & 11,06 & 2.174 .200 & 10,15 \\
\hline 6 letras & 1.804 .230 & 8,28 & 1.579 .171 & 7,37 \\
\hline 7 letras & 1.655 .522 & 7,60 & 1.439 .280 & 6,72 \\
\hline 8 letras & 1.150 .188 & 5,28 & 1.162 .258 & 5,42 \\
\hline 9 letras & 830.798 & 3,81 & 788.230 & 3,68 \\
\hline 10 letras & 533.148 & 2,45 & 595.246 & 2,78 \\
\hline Más de 10 letras & 940.426 & 4,32 & 421.465 & 1,97 \\
\hline
\end{tabular}

Tabla 8. Cantidad de palabras según el número de letras que las integran

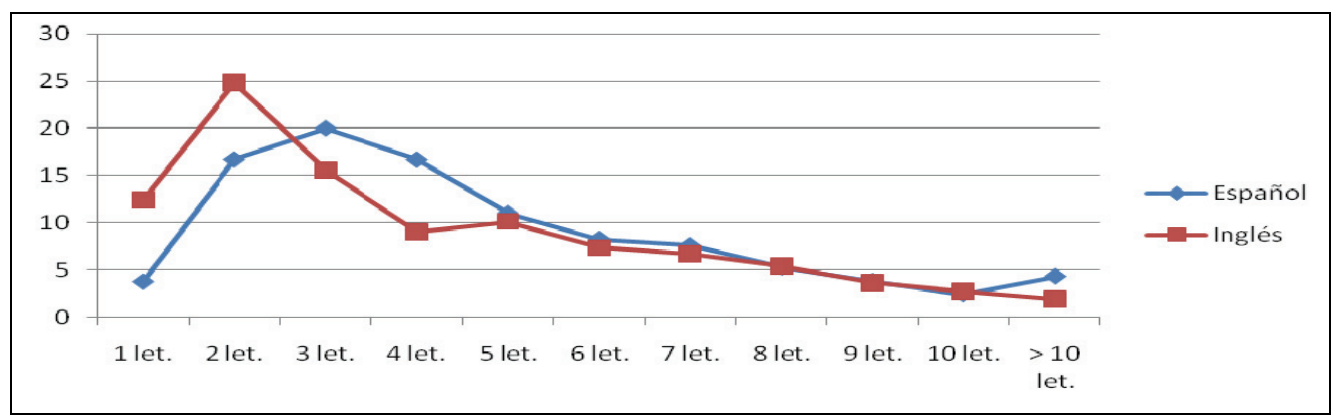

Gráfico 6. Distribución comparativa (español-inglés) de palabras según el número de letras

\subsection{USO DE VOCALES Y CONSONANTES}

En las aplicaciones del lenguaje a diferentes ámbitos industriales y computacionales es muy importante conocer determinados aspectos cuantitativos básicos, como son la frecuencia de vocales y de consonantes y la tipología y frecuencia de determinadas secuencias de letras. Estos hechos son decisivos a la hora de elaborar estadísticas para la corrección ortográfica, por ejemplo, o para la síntesis del habla. Respecto al uso de cada letra en inglés y en español, hay diferencias significativas tanto en lo referido a las vocales como a las consonantes. Llama la atención la diferencia de frecuencia en 
el uso de la vocal 'a' en cada idioma; pero el resto de vocales no presenta contrastes notables (Tabla 9 y Gráfico 7). También existen diferencias relevantes en la distribución de las vocales a final de palabra, especialmente si se trata de la 'a' y la 'o', tal y como reflejan los datos de la Tabla 9 y el Gráfico 8.

\begin{tabular}{|c|c|c|c|c|}
\hline \multirow{2}{*}{ Vocales } & \multicolumn{2}{|c|}{ Inglés } & \multicolumn{2}{c|}{ Español } \\
\cline { 2 - 5 } & $\%$ & $\begin{array}{c}\% \\
\text { (posición final) }\end{array}$ & $\%$ & $\begin{array}{c}\% \\
\text { (posición final) }\end{array}$ \\
\hline $\mathrm{E}$ & 11,8 & 3,53 & 12 & 2,78 \\
\hline $\mathrm{A}$ & 7,7 & 0,57 & 11,5 & 2,98 \\
\hline $\mathrm{O}$ & 7,2 & 0,82 & 8,1 & 1,95 \\
\hline $\mathrm{I}$ & 7,3 & 0,12 & 7 & 0,07 \\
\hline U & 2,6 & 0,06 & 3,6 & 0,09 \\
\hline TOTAL & 36,6 & 5,1 & 42,1 & 7,87 \\
\hline
\end{tabular}

Tabla 9. Uso y distribución de las vocales en inglés y en español

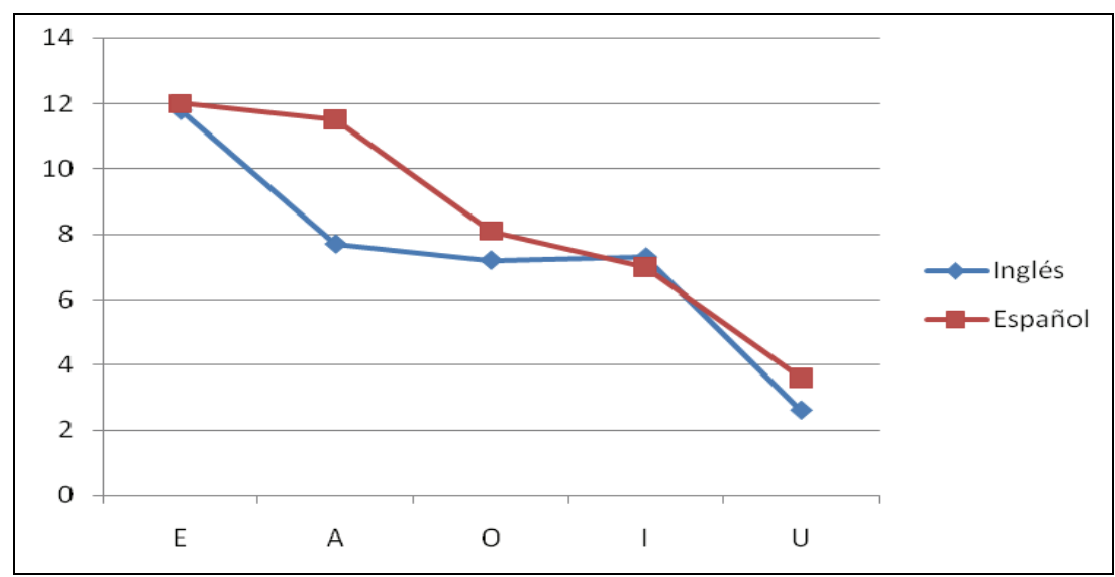

Gráfico 7. Distribución comparativa (español-inglés) del uso de las vocales 


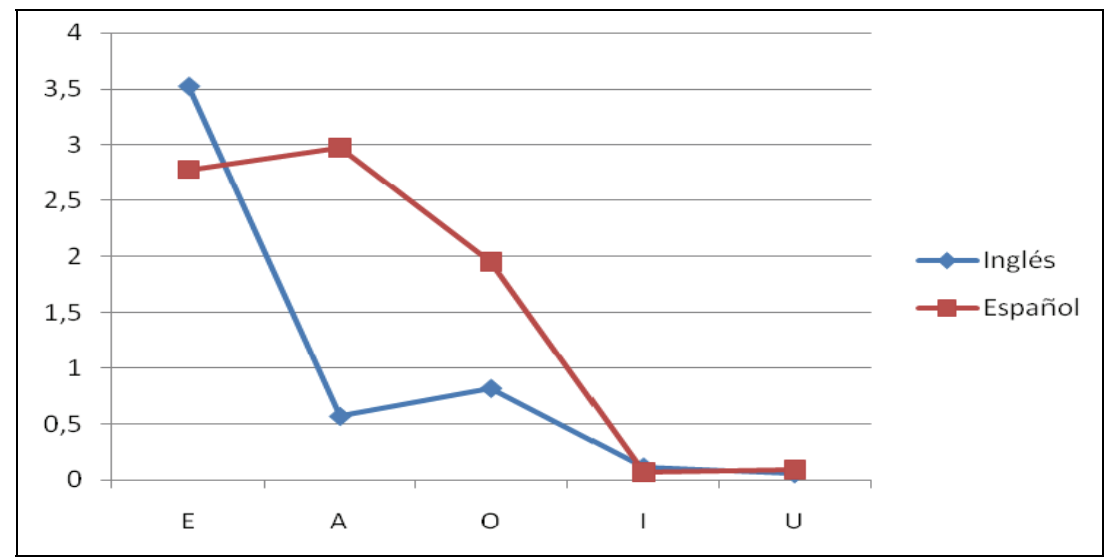

Gráfico 8. Distribución comparativa (español-inglés) del uso de las vocales en posición final

Respecto a las consonantes, los corpus analizados reflejan los siguientes datos (en orden de frecuencia):

\begin{tabular}{|c|c|c|}
\hline Consonantes & Inglés (\%) & Español (\%) \\
\hline T & 8,9 & 4,3 \\
\hline N & 6,7 & 6,7 \\
\hline S & 6,5 & 7 \\
\hline R & 5,9 & 6,2 \\
\hline H & 5 & 0,6 \\
\hline P & 3,5 & 5 \\
\hline F & 1,9 & 2,6 \\
\hline M & 2,1 & 0,7 \\
\hline W & 2,3 & 2,5 \\
\hline Y & 1,7 & 0,006 \\
\hline V & 1,6 & 0,8 \\
\hline K & 1,9 & 0,99 \\
\hline Q & 0,9 & 0,93 \\
\hline X & 0,5 & 0,01 \\
\hline J & 0,09 & 0,8 \\
\hline Z & 0,19 & 0,14 \\
\hline N & 0,2 & 0,44 \\
\hline B & 0,07 & 0,35 \\
\hline
\end{tabular}

Tabla 10. Frecuencia de consonantes en inglés y en español 
Obsérvese que en la tabla anterior se han sombreado los casos con las diferencias más significativas. Especialmente revelador resulta la diferencia de uso en las consonantes $t, h, f \mathrm{y} w$. En conjunto, sin embargo, predominan las semejanzas entre ambas lenguas (Gráfico 10).

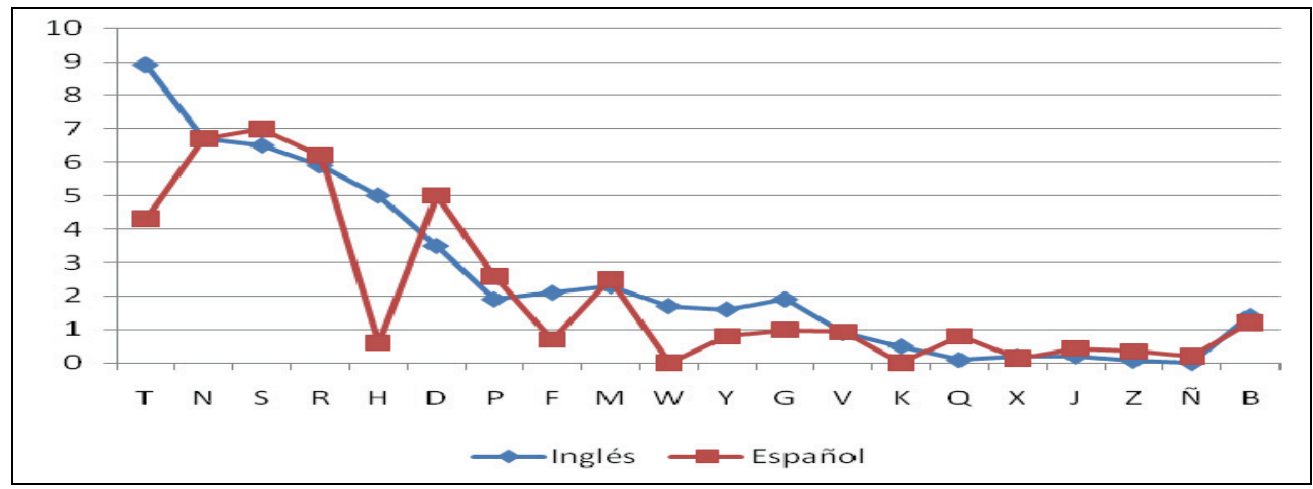

Gráfico 9. Distribución comparativa (español-inglés) del uso de las consonantes

En lo que se refiere a dígrafos consonánticos, dos de ellos contrastan en ambos idiomas, la $c h$ (con notables diferencias) y la $s p$ :

\begin{tabular}{|c|c|c|}
\hline Dígrafos & Inglés (\%) & Español (\%) \\
\hline CH & 0,5 & 0,15 \\
\hline SP & 0,15 & 0,2 \\
\hline
\end{tabular}

Tabla 11. Dígrafos: $c h$ y $s p$

\subsection{NATURALEZA DE LAS PALABRAS MÁS FRECUENTES Y SU DISTRIBUCIÓN}

Aparte del estudio comparativo de las frecuencias léxicas, cabe también preguntarse si esas mismas frecuencias se distribuyen homogéneamente en ambos idiomas. A tal fin, es preciso seleccionar un determinado tramo de frecuencia en cada lengua y analizar las palabras que lo integran. En la Tabla 12 se ofrece la lista de las 100 formas más frecuentes en inglés y en español, especificando la frecuencia de cada forma en su respectivo corpus:

\begin{tabular}{|c|c|c|c|c|c|c|c|c|c|}
\hline & \multicolumn{2}{|c|}{ Inglés } & \multicolumn{2}{c|}{ Español } & & \multicolumn{2}{c|}{ Inglés } & \multicolumn{2}{c|}{ Español } \\
\cline { 2 - 7 } \cline { 7 - 9 } & Frecuencia & Forma & Frecuencia & Forma & & Frecuencia & Forma & Frecuencia & Forma \\
\hline 1 & 1263621 & The & 1216593 & De & 51 & 44243 & Your & 28013 & Había \\
\hline 2 & 620841 & Of & 770656 & La & 52 & 44169 & Do & 27671 & Nos \\
\hline 3 & 584526 & And & 673494 & Que & 53 & 43763 & Up & 27604 & Años \\
\hline 4 & 565223 & To & 563139 & Y & 54 & 43620 & No & 26605 & Tiene \\
\hline 5 & 480032 & A & 557608 & El & 55 & 42778 & Out & 26062 & Hasta \\
\hline
\end{tabular}




\begin{tabular}{|c|c|c|c|c|c|c|c|c|c|}
\hline 6 & 398530 & In & 522624 & En & 56 & 40807 & Her & 25753 & Desde \\
\hline 7 & 264186 & That & 429826 & A & 57 & 39222 & Some & 25473 & $\mathrm{Te}$ \\
\hline 8 & 234752 & Is & 327038 & Los & 58 & 39011 & Said & 25374 & Eso \\
\hline 9 & 227414 & It & 265864 & $\mathrm{Se}$ & 59 & 36647 & Them & 24739 & Fue \\
\hline 10 & 190559 & For & 233880 & No & 60 & 35753 & Time & 24580 & Todos \\
\hline 11 & 172430 & You & 222746 & Un & 61 & 34890 & People & 23953 & Puede \\
\hline 12 & 154364 & On & 215618 & Las & 62 & 34832 & Other & 23722 & Pues \\
\hline 13 & 147579 & Was & 211604 & Del & 63 & 34319 & $\mathrm{Er}$ & 23513 & Han \\
\hline 14 & 141415 & With & 202115 & Por & 64 & 34030 & Two & 23160 & Así \\
\hline 15 & 138725 & $\mathrm{Be}$ & 183781 & Con & 65 & 33465 & Like & 23031 & Bien \\
\hline 16 & 133777 & As & 181191 & Una & 66 & 33431 & My & 21350 & Vez \\
\hline 17 & 115053 & Are & 176187 & Es & 67 & 33309 & Into & 21134 & $\mathrm{Ni}$ \\
\hline 18 & 110872 & $\mathrm{He}$ & 137537 & Lo & 68 & 32539 & Then & 20690 & Sólo \\
\hline 19 & 109124 & At & 135083 & Para & 69 & 31961 & Well & 20130 & Ahora \\
\hline 20 & 104301 & This & 127901 & $\mathrm{Su}$ & 70 & 31770 & Very & 19975 & Él \\
\hline 21 & 103977 & Have & 113580 & $\mathrm{Al}$ & 71 & 31522 & Its & 19047 & Uno \\
\hline 22 & 103853 & $\mathrm{We}$ & 102577 & Como & 72 & 31353 & Now & 18868 & Parte \\
\hline 23 & 100022 & By & 93074 & Más & 73 & 30823 & Than & 18736 & Ese \\
\hline 24 & 99428 & They & 72694 & Pero & 74 & 30335 & Just & 18128 & Tiempo \\
\hline 25 & 97517 & But & 69189 & $\mathrm{Me}$ & 75 & 30102 & Only & 18086 & Vida \\
\hline 26 & 90445 & Or & 61247 & $\mathrm{Le}$ & 76 & 29335 & New & 17886 & Mismo \\
\hline 27 & 90188 & From & 55331 & $\mathrm{Ha}$ & 77 & 29321 & Think & 17405 & Otro \\
\hline 28 & 89997 & Not & 54089 & Sus & 78 & 28725 & Any & 17357 & Día \\
\hline 29 & 73227 & There & 53544 & $\mathrm{Si}$ & 79 & 28616 & Know & 17225 & Cada \\
\hline 30 & 72231 & An & 47042 & Yo & 80 & 27700 & These & 17146 & Hacer \\
\hline 31 & 71331 & His & 45649 & $\mathrm{Ya}$ & 81 & 27575 & May & 17000 & Siempre \\
\hline 32 & 71104 & Which & 42028 & Este & 82 & 27526 & Could & 16891 & Entonces \\
\hline 33 & 67826 & One & 38804 & Porque & 83 & 26846 & Our & 16844 & Nada \\
\hline 34 & 64639 & Will & 38398 & Muy & 84 & 26760 & Also & 16768 & Donde \\
\hline 35 & 63656 & All & 38351 & Todo & 85 & 26693 & First & 16764 & Esa \\
\hline 36 & 62922 & $\mathrm{Had}$ & 37518 & Cuando & 86 & 26178 & $\mathrm{Me}$ & 16658 & Hace \\
\hline 37 & 60724 & If & 37472 & Qué & 87 & 25206 & How & 16574 & Bueno \\
\hline 38 & 59822 & Can & 36372 & Sin & 88 & 25144 & Over & 16543 & Decir \\
\hline 39 & 57838 & Has & 36067 & Son & 89 & 25092 & Because & 16504 & Tan \\
\hline 40 & 57311 & So & 35467 & Sobre & 90 & 25002 & Him & 16485 & Otra \\
\hline 41 & 57144 & What & 34596 & Está & 91 & 24326 & $\mathrm{Re}$ & 16388 & Esto \\
\hline 42 & 55547 & Their & 33752 & También & 92 & 24308 & Get & 15823 & Después \\
\hline 43 & 54671 & Were & 33333 & Esta & 93 & 23554 & See & 15733 & Ella \\
\hline 44 & 50627 & About & 33141 & Hay & 94 & 22873 & After & 15282 & Menos \\
\hline 45 & 47932 & Been & 33067 & Sí & 95 & 22668 & Most & 15269 & Tanto \\
\hline 46 & 47928 & More & 31747 & Entre & 96 & 22593 & Don't & 15232 & Otros \\
\hline 47 & 47604 & Would & 31317 & Ser & 97 & 22585 & Where & 15203 & Mundo \\
\hline 48 & 47299 & When & 31293 & Era & 98 & 22230 & Should & 15182 & Aquí \\
\hline 49 & 46355 & Who & 30871 & Mi & 99 & 21642 & Many & 15163 & $\mathrm{Va}$ \\
\hline 50 & 44866 & She & 29334 & Dos & 100 & 21470 & Way & 14904 & Poco \\
\hline
\end{tabular}

Tabla 12. Las 100 formas más frecuentes en inglés y en español

Una primera valoración comparativa muestra un comportamiento aparentemente similar, dibujando una curva de más a menos y a un ritmo exponencial negativo; es decir, una función hiperbólica, similar a una cotangente hiperbólica (Gráfico 10). 


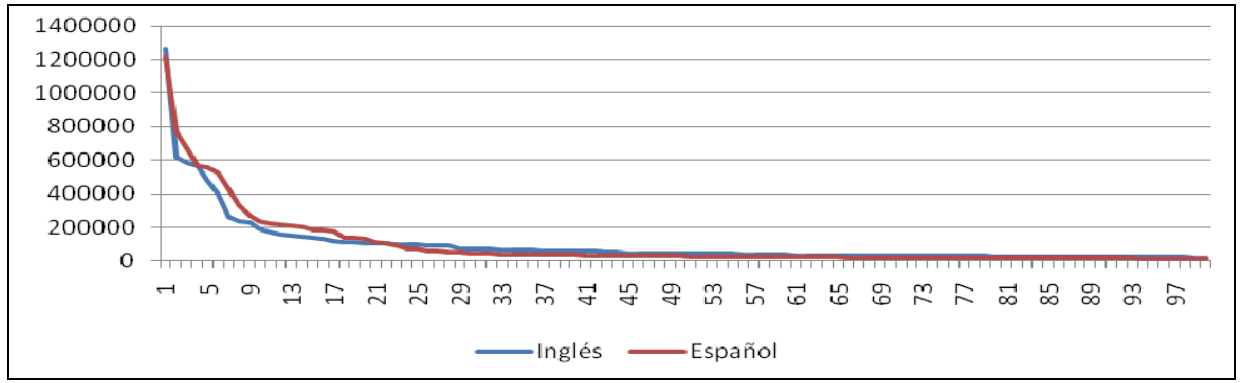

Gráfico 10. Distribución comparativa (español-inglés) de las frecuencias de las palabras más usadas

Un análisis más detallado, centrado en las diferencias entre frecuencias, revela diferentes patrones de comportamiento entre el inglés y el español:

1. Hay oscilaciones importantes entre las aproximadamente 21 formas más usadas (salvo la primera y la cuarta), a favor del español; es decir, el español hace un uso más extensivo de las palabras más usadas.

2. Esta tendencia se torna a favor del inglés de la palabra 22 en adelante, o lo que es lo mismo, con palabras cuyas frecuencias absolutas están en torno a $100.000 \approx$ $0,5 \%$ de frecuencia relativa). A partir de este punto el inglés se vuelve más repetitivo que el español (Gráfico 11).

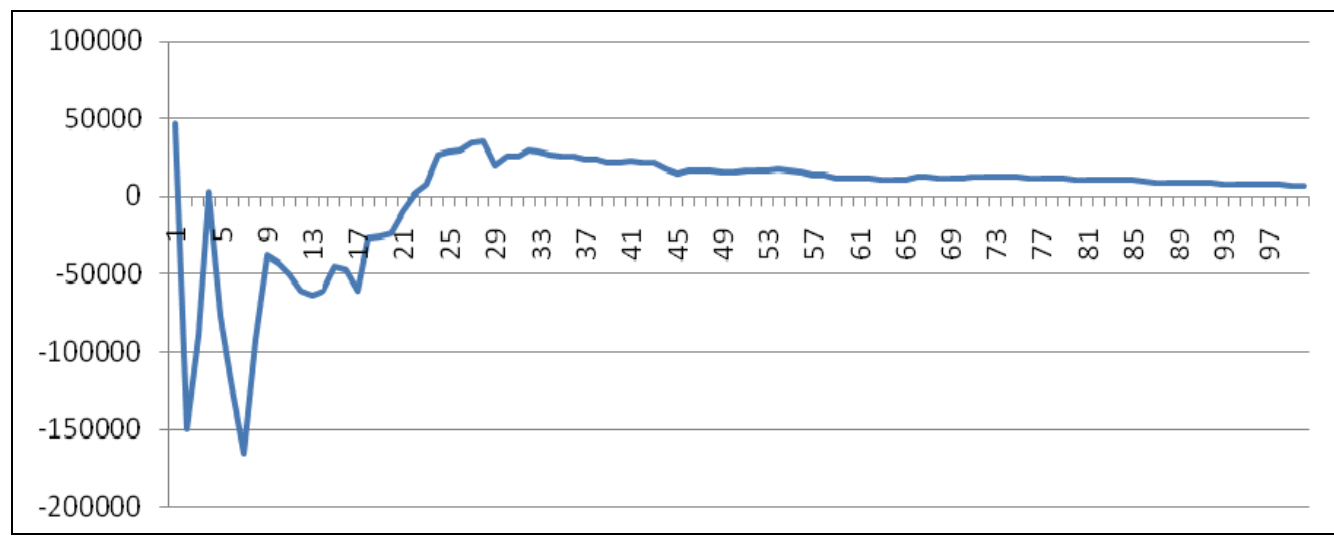

Gráfico 11. Distribución comparativa y diferencial de las frecuencias de las palabras más usadas (inglés y español)

En cuanto a los términos de mayor frecuencia, las palabras funcionales ocupan los primeros puestos en ambas lenguas, si bien es verdad que su orden en la lista no es plenamente coincidente. El término inglés the (artículo) es la palabra más frecuente, que se corresponde en español con de (preposición). Aunque en realidad esta diferencia en categoría gramatical se debe a razones flexivas. Si sumamos todas las 
formas flexivas del artículo determinado en español, en singular y en plural (el, la, los, las), el resultado es superior al the inglés: la suma asciende a 1.870 .920 veces (un $8,58 \%$ del total de palabras usadas en los 21 millones), muy por encima de la preposición de $(5,53 \%)$ o del artículo the $(5,89 \%)$. A su vez, la segunda palabra más frecuente en inglés, of (preposición), se usa casi tres veces por cada cien palabras, mientras que su equivalente española, de, casi la duplica en el uso (Tabla 13).

\begin{tabular}{|l|c|c|}
\hline & Inglés & Español \\
\hline $\begin{array}{l}\text { The frente a } \\
\text { El/la/los/las }\end{array}$ & $5,89 \%$ & $8,58 \%$ \\
\hline Of frente a De & $2,89 \%$ & $5,53 \%$ \\
\hline
\end{tabular}

Tabla 13. Voces más frecuentes en inglés y español: the y of; de y el/la/los/las

También destaca el hecho de que en inglés las formas verbales más frecuentes son, $\mathrm{y}$ en este orden, was, be, are, have, mientras que el español prefiere es, ha, hay, habia, mostrando una inversión parcial respecto a la preeminencia de (to) be, seguido de (to) have.

Respecto a los sustantivos, es interesante advertir que estos aparecen en posiciones sorprendentemente retrasadas: time ocupa la posición 60 en la lista, y años la posición 53. La preeminencia de las voces funcionales y de las formas verbales es evidente en ambos idiomas.

La comparación de la frecuencia de los lemas (Tabla 14 y Gráfico 11) no varía en algunos de los rasgos más sobresalientes. Destaca el hecho de que, globalmente, las frecuencias son muy similares en ambos idiomas y que las palabras funcionales siguen en cabeza:

1. El lema menos frecuente (de los 100 primeros) presenta una diferencia de unas 2.000 ocurrencias a favor del inglés.

2. El verbo to be dobla con creces la frecuencia de ser y estar juntos.

3. To have casi dobla la frecuencia de haber, mientras que to do y hacer son muy similares en este parámetro.

4. En las cien primeras voces, el español incluye 40 términos léxicos, mientras que el inglés sólo cuenta con 29.

\begin{tabular}{|c|c|c|c|c|c|c|c|c|c|}
\hline & \multicolumn{2}{|c|}{ Inglés } & \multicolumn{2}{c|}{ Español } & & \multicolumn{2}{c|}{ Inglés } & \multicolumn{2}{c|}{ Español } \\
\cline { 2 - 6 } \cline { 7 - 10 } & Frecuencia & Lema & Frecuencia & Lema & & Frecuencia & Lema & Frecuencia & Lema \\
\hline 1 & 1263621 & the & 1870920 & el & 51 & 38332 & see & 30482 & mismo \\
\hline 2 & 847926 & be & 1216684 & de & 52 & 38553 & know & 30463 & dar \\
\hline 3 & 618888 & of & 710981 & que & 53 & 36685 & time & 29720 & parir \\
\hline 4 & 537572 & and & 563142 & y & 54 & 35844 & take & 29225 & parar \\
\hline 5 & 437273 & a & 522628 & en & 55 & 34682 & them & 28937 & bueno \\
\hline 6 & 384863 & in & 429846 & a & 56 & 34234 & some & 28889 & querer \\
\hline 7 & 324170 & to & 319626 & ser & 57 & 33677 & could & 28159 & día \\
\hline
\end{tabular}




\begin{tabular}{|c|c|c|c|c|c|c|c|c|c|}
\hline 8 & 275127 & have & 316814 & un & 58 & 33464 & so & 27673 & nos \\
\hline 9 & 218037 & it & 301055 & lo & 59 & 33002 & him & 27666 & ha \\
\hline 10 & 205866 & to & 233886 & no & 60 & 32786 & year & 26062 & hasta \\
\hline 11 & 177575 & for & 211605 & del & 61 & 32693 & into & 25752 & desde \\
\hline 12 & 176819 & I & 202117 & por & 62 & 32616 & its & 25481 & te \\
\hline 13 & 152079 & that & 183787 & con & 63 & 32130 & then & 25461 & deber \\
\hline 14 & 139099 & you & 165596 & saber & 64 & 30776 & think & 24747 & bien \\
\hline 15 & 136251 & he & 139412 & haber & 65 & 30523 & my & 23724 & pues \\
\hline 16 & 136147 & on & 132957 & se & 66 & 30374 & come & 23655 & entrar \\
\hline 17 & 135005 & with & 113593 & al & 67 & 29523 & than & 22848 & alguno \\
\hline 18 & 111919 & do & 111401 & estar & 68 & 29205 & more & 22824 & ello \\
\hline 19 & 106832 & at & 104468 & tener & 69 & 28910 & about & 22301 & nuestro \\
\hline 20 & 103434 & by & 98029 & hacer & 70 & 28760 & now & 21881 & esa \\
\hline 21 & 93097 & not & 93082 & más & 71 & 28012 & last & 21558 & llegar \\
\hline 22 & 92389 & this & 89433 & este & 72 & 27666 & your & 21136 & ni \\
\hline 23 & 91924 & but & 86639 & si & 73 & 27630 & me & 21102 & partir \\
\hline 24 & 86906 & from & 85501 & todo & 74 & 27405 & no & 20690 & sólo \\
\hline 25 & 86688 & they & 82940 & 0 & 75 & 27037 & other & 20677 & donde \\
\hline 26 & 85379 & his & 82280 & como & 76 & 26283 & give & 20592 & pasar \\
\hline 27 & 76862 & that & 81111 & poder & 77 & 25703 & just & 20523 & tiempo \\
\hline 28 & 76051 & she & 81056 & para & 78 & 25678 & should & 20359 & político \\
\hline 29 & 74761 & or & 79162 & ir & 79 & 25088 & these & 20132 & ahora \\
\hline 30 & 74406 & which & 76696 & decir & 80 & 25086 & people & 19981 & él \\
\hline 31 & 72832 & as & 72713 & pero & 81 & 24976 & also & 19844 & primero \\
\hline 32 & 71607 & we & 71898 & uno & 82 & 24890 & well & 19741 & tanto \\
\hline 33 & 68612 & an & 70274 & me & 83 & 24731 & any & 19733 & poner \\
\hline 34 & 66703 & say & 68077 & le & 84 & 24425 & only & 19628 & poco \\
\hline 35 & 59456 & will & 58391 & unir & 85 & 23104 & new & 19569 & ese \\
\hline 36 & 54469 & would & 50682 & otro & 86 & 22982 & very & 19428 & país \\
\hline 37 & 53223 & can & 47054 & yo & 87 & 22731 & when & 18721 & vida \\
\hline 38 & 52217 & if & 45656 & ya & 88 & 22604 & may & 18518 & usted \\
\hline 39 & 52183 & their & 40492 & año & 89 & 22527 & way & 18284 & hombre \\
\hline 40 & 49908 & go & 39674 & porque & 90 & 22211 & look & 18243 & sobrar \\
\hline 41 & 49893 & what & 39033 & comer & 91 & 22018 & like & 18077 & son \\
\hline 42 & 47892 & there & 38854 & cuando & 92 & 21764 & use & 17839 & parecer \\
\hline 43 & 46147 & all & 38759 & ver & 93 & 21742 & her & 17733 & sobre \\
\hline 44 & 44188 & get & 38399 & muy & 94 & 21704 & such & 17626 & quien \\
\hline 45 & 43651 & her & 38016 & $\mathrm{mi}$ & 95 & 20701 & how & 17336 & nuevo \\
\hline 46 & 43453 & make & 36372 & $\sin$ & 96 & 20600 & because & 17226 & cada \\
\hline 47 & 41086 & who & 34593 & mucho & 97 & 20524 & when & 17015 & siempre \\
\hline 48 & 40393 & as & 33765 & también & 98 & 20316 & as & 16964 & llevar \\
\hline 49 & 40363 & out & 31468 & vez & 99 & 20130 & good & 16893 & entonces \\
\hline 50 & 39085 & up & 31399 & eso & 100 & 19779 & find & 16842 & hablar \\
\hline
\end{tabular}

Tabla 14. Listado de los 100 lemas más frecuentes 


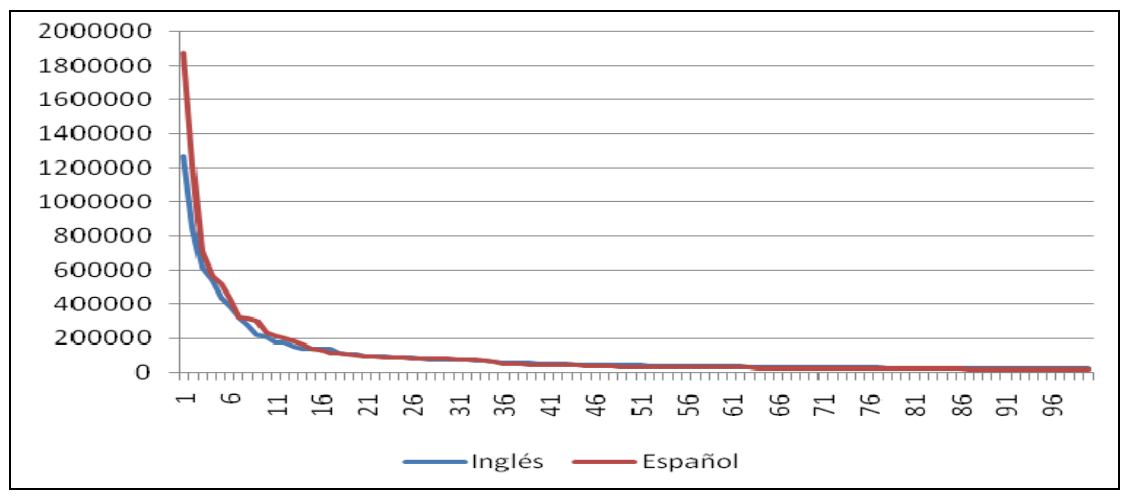

Gráfico 11. Distribución comparativa (español-inglés) de las frecuencias de los lemas más usados

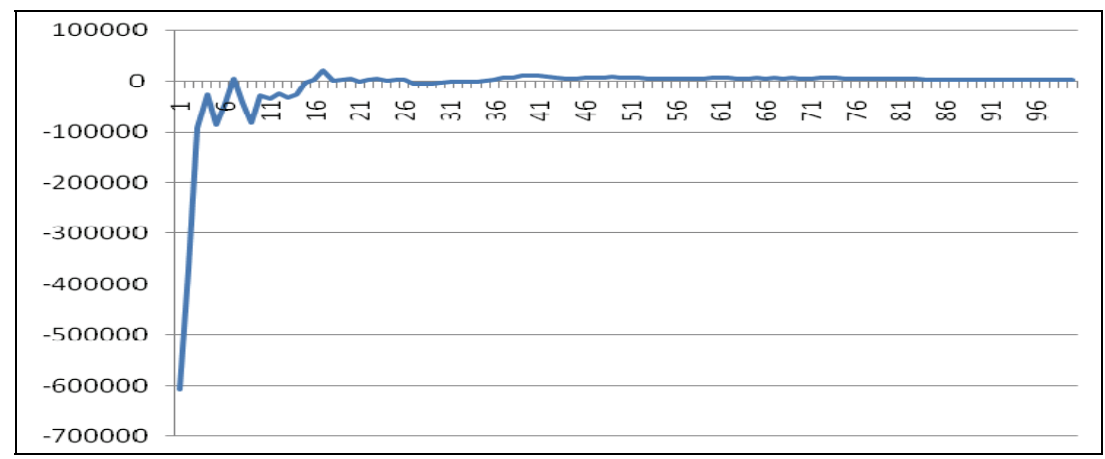

Gráfico 12. Distribución comparativa y diferencial de las frecuencias de los lemas más usadas

\section{TIPIFICACIÓN PROTOTÍPICA DE UN TEXTO EN ESPAÑOL Y EN INGLÉS}

A tenor de los datos obtenidos de las dos lenguas, español e inglés, es posible mostrar el perfil de un texto prototipo en cada una de las lenguas mencionadas. Así un texto de unas 25.000 palabras en español y otro de igual tamaño en inglés, reflejarían los siguientes rasgos y composición léxica interna:

\begin{tabular}{|l|c|c|c|}
\hline & Español & Inglés & Diferencia en \% \\
\hline Palabras (tokens) & 25.000 & 25.000 & - \\
\hline Formas (types) & 7.406 & 5.921 & $25,08^{15}$ \\
\hline
\end{tabular}

${ }^{15}$ Los valores positivos señalan índices a favor del español y los negativos a favor del inglés. 


\begin{tabular}{|c|c|c|c|c|}
\hline \multicolumn{2}{|c|}{ Ratio de formas nuevas $^{16}$} & 29 & 23 & 26,09 \\
\hline \multicolumn{2}{|c|}{ Ratio de repetición de formas } & 3,37 & 4,22 & $-20,14$ \\
\hline \multirow{5}{*}{$\begin{array}{l}\text { Distribución } \\
\text { de formas por } \\
\text { tramos de } \\
\text { frecuencia }\end{array}$} & 1 & 9.760 & 8.685 & 12,38 \\
\hline & $2-5$ & 6.098 & 6.495 & $-6,11$ \\
\hline & $6-20$ & 5.038 & 5.060 & $-0,43$ \\
\hline & $21-100$ & 2.653 & 2.985 & $-11,12$ \\
\hline & $101-1000$ & 1.250 & 1.448 & $-13,67$ \\
\hline \multicolumn{2}{|l|}{ Palabras léxicas } & 19.413 & 21.065 & $-7,84$ \\
\hline \multicolumn{2}{|c|}{ Ratio de palabras léxicas } & 77,65 & 84,26 & $-7,84$ \\
\hline \multicolumn{2}{|c|}{ Palabras funcionales } & 5.588 & 3.935 & 42,01 \\
\hline \multicolumn{2}{|c|}{ Ratio de palabras funcionales } & 22,35 & 15,74 & 41,99 \\
\hline \multicolumn{2}{|c|}{ Oraciones } & 1.196 & 1.329 & $-10,01$ \\
\hline \multicolumn{2}{|c|}{ Ratio de palabras por oraciones } & 20,90 & 18,81 & 11,11 \\
\hline \multirow{11}{*}{$\begin{array}{l}\text { Cantidad de } \\
\text { palabras según } \\
\text { el número de } \\
\text { letras }\end{array}$} & 1 letra & 938 & 3.100 & $-69,74$ \\
\hline & 2 letras & 4.180 & 6.225 & $-32,85$ \\
\hline & 3 letras & 5.010 & 3.893 & 28,69 \\
\hline & 4 letras & 4.175 & 2.263 & 84,49 \\
\hline & 5 letras & 2.765 & 2.538 & 8,94 \\
\hline & 6 letras & 2.070 & 1.843 & 12,32 \\
\hline & 7 letras & 1.900 & 1.680 & 13,10 \\
\hline & 8 letras & 1.320 & 1.355 & $-2,58$ \\
\hline & 9 letras & 953 & 920 & 3,59 \\
\hline & 10 letras & 613 & 695 & $-11,80$ \\
\hline & $>10$ letras & 1.080 & 493 & 119,07 \\
\hline \multirow{5}{*}{$\begin{array}{l}\text { Uso de vocales } \\
\text { en palabras }\end{array}$} & $\mathrm{A}$ & 3.000 & 2.950 & 1,69 \\
\hline & $\mathrm{E}$ & 2.875 & 1.925 & 49,35 \\
\hline & $\mathrm{I}$ & 2.025 & 1.800 & 12,50 \\
\hline & $\mathrm{O}$ & 1.750 & 1.825 & $-4,11$ \\
\hline & $\mathrm{U}$ & 900 & 650 & 38,46 \\
\hline \multirow{5}{*}{$\begin{array}{l}\text { Uso de vocales } \\
\text { en palabras } \\
\text { (posición final) }\end{array}$} & $\mathrm{A}$ & 695 & 883 & $-21,29$ \\
\hline & $\mathrm{E}$ & 745 & 143 & 420,98 \\
\hline & $\mathrm{I}$ & 488 & 205 & 138,05 \\
\hline & $\mathrm{O}$ & 18 & 30 & $-40,00$ \\
\hline & $\mathrm{U}$ & 23 & 15 & 53,33 \\
\hline \multirow{8}{*}{$\begin{array}{l}\text { Uso de } \\
\text { consonantes } \\
\text { en palabras }\end{array}$} & $\mathrm{T}$ & 1075 & 2225 & $-51,69$ \\
\hline & $\mathrm{N}$ & 1675 & 1675 & 0,00 \\
\hline & $\mathrm{S}$ & 1750 & 1625 & 7,69 \\
\hline & $\mathrm{R}$ & 1550 & 1475 & 5,08 \\
\hline & $\mathrm{H}$ & 150 & 1250 & $-88,00$ \\
\hline & $\mathrm{D}$ & 1250 & 875 & 42,86 \\
\hline & $\mathrm{P}$ & 650 & 475 & 36,84 \\
\hline & $\mathrm{F}$ & 175 & 525 & $-66,67$ \\
\hline
\end{tabular}

\footnotetext{
${ }^{16}$ Las ratios se expresan por cada 100 ítems.
} 


\begin{tabular}{|c|c|c|c|c|}
\hline \multirow{4}{*}{} & $\mathrm{M}$ & 625 & 575 & 8,70 \\
\cline { 2 - 5 } & $\mathrm{W}$ & 2 & 425 & $-99,53$ \\
\cline { 2 - 5 } & $\mathrm{Y}$ & 200 & 400 & $-50,00$ \\
\cline { 2 - 5 } & $\mathrm{G}$ & 248 & 475 & $-47,79$ \\
\cline { 2 - 5 } & $\mathrm{V}$ & 233 & 225 & 3,56 \\
\cline { 2 - 5 } & $\mathrm{K}$ & 3 & 125 & $-97,60$ \\
\cline { 2 - 5 } & $\mathrm{Q}$ & 200 & 23 & 769,57 \\
\cline { 2 - 5 } & $\mathrm{X}$ & 35 & 48 & $-27,08$ \\
\cline { 2 - 5 } & $\mathrm{J}$ & 110 & 50 & 120,00 \\
\cline { 2 - 5 } & $\mathrm{Z}$ & 88 & 18 & 388,89 \\
\hline \multirow{4}{*}{$\begin{array}{l}\text { Uso de } \\
\text { dígrafos }\end{array}$} & $\mathrm{N}$ & 48 & 0 & $-14,29$ \\
\cline { 2 - 5 } & $\mathrm{B}$ & 300 & 350 & $-69,60$ \\
\hline
\end{tabular}

Tabla 15. Resumen cuantitativo del español versus inglés

En resumen, el español es más prolijo que el inglés en formas distintas (types) y tiene, por tanto, una mayor ratio de variedad de formas. No obstante y a pesar de esta mayor diversidad de formas, el español usa un repertorio léxico menos variado respecto al inglés, y tiende a repetir con mayor frecuencia las palabras léxicas que utiliza.

La distribución de grupos de palabras por frecuencias también tiene patrones diferenciados en ambas lenguas. Las diferencias se hacen especialmente patentes en los extremos de la banda de frecuencia: en las palabras 'raras' (palabras que ocurren una sola vez: hapax legomena), más frecuentes en español, y en las palabras más comunes, más frecuentes en inglés, especialmente a partir de la frecuencia de 8 palabras por cada $10.000^{17}$ (en muestras de 25.000). Todo ello indica que el español hace un mayor acopio de palabras 'raras' y repite comparativamente menos las más frecuentes.

Aunque la sintaxis y el discurso no son el objeto de nuestro estudio, la longitud media de las oraciones en ambos idiomas apunta a que el español formula y construye periodos oracionales más largos que el inglés, a la vez que contiene, tal y como se vio con anterioridad, una mayor concentración de palabras funcionales.

En cuanto al patrón distributivo de las palabras atendiendo a su magnitud gráfica, el comportamiento en ambas lenguas es bastante dispar: el uso de palabras de uno o dos caracteres es más frecuente en inglés que en español; la tendencia se torna a favor del español en palabras con tres y cuatro letras y se agudiza en el uso de palabras polisilábicas con más de diez caracteres, en cuyo ámbito la lengua española duplica a la inglesa.

\footnotetext{
${ }^{17}$ Este dato se ha obtenido dividiendo 21 por $25.000 ; 21: 25.000=0,00084$.
} 


\section{ALGUNAS CONSIDERACIONES FINALES}

El análisis llevado a cabo en este artículo ha sido de carácter cuantitativo, basado en dos corpus equivalentes de poco más de 20 millones de palabras cada uno. Las proyecciones realizadas deben ser entendidas, por tanto, en su justa dimensión, con las limitaciones y bondades propias de las muestras utilizadas. Cabe afirmar, sin embargo, que aunque un corpus más amplio habría aportado una mayor precisión y refinamiento en algunos de los datos extraídos, lo esencial de lo expresado a lo largo de estas páginas no habría cambiado.

De otra parte, no cabe la menor duda de que los datos cuantitativos inciden directamente en los datos cualitativos que podrían extraerse. La frecuencia de determinadas palabras, por ejemplo, no es inocua: refleja el índice de uso de los conceptos que aquellas conllevan y, por ende, el grado de importancia que dichos conceptos tienen en la sociedad de hablantes nativos.

Con frecuencia se enfatizan las diferencias entre lenguas. Pero nuestro estudio demuestra que también habría que poner de relieve lo que comparten o tienen en común. Las lenguas tienden a diferenciarse en aspectos formales, pero mantienen muchos otros elementos básicos, de carácter estructural. La comparación del español y del inglés no deja lugar a dudas sobre los rasgos que ambas lenguas comparten en aspectos léxicos y estructurales, aspectos que no deberían dejarse de lado en estudios contrastivos. Las semejanzas o diferencias pueden referirse a la cuantía léxica, a la distribución léxica, a la longitud de las oraciones, a la longitud de las palabras, al uso de vocales y consonantes, al peso de las palabras funcionales y léxicas, a los sonidos, y en general, a la simetría en parámetros tanto ortográficos como morfológicos y sintácticos. Existen también semejanzas en la organización conceptual que subyace en las palabras, pero este tema requeriría disponer de datos que aún no son fáciles de obtener automáticamente con las herramientas de análisis con que contamos.

Los estudios contrastivos entre lenguas no gozan actualmente de la popularidad que gozaron en la década de los sesenta, pero las recopilaciones textuales que actualmente están a nuestro alcance permiten alcanzar resultados no solamente más ambiciosos, sino también más fiables. En esa línea de futuro pretendemos situar nuestro trabajo, invitando a retomar una línea de investigación que la disponibilidad de los corpus augura como de gran utilidad, además de prometedora.

\section{REFERENCIAS}

Barnbrook, G. (1996). Language and Computers. Edinburgh: Edinburgh University Press.

Cantos, P. (1995). Tratamiento informático y obtención de resultados. In Sánchez, ed., 39-70.

Cantos, P. (2000). Investigating Type-token Regression and its Potential for Automated Text Discrimination. Cuadernos de Filología Inglesa 9(2), 71-91. 
Cantos, P. and A. Sánchez (2001). Lexical Constellations: What Collocates Fail to Tell. International Journal of Corpus Linguistics 6(2), 199-228.

Castagno, J. P., ed. (2006). Encyclopedia Americana. Connecticut: Grolier Incorporated.

Chipere, N., D. Malvern, B. Richards and P. Duran (2001). Using a Corpus of School Children's Writing to Investigate the Development of Vocabulary Diversity. In Rayson, Wilson, McEnery, Hardie and Khoja, eds., 126-133.

Church, K.W., W. Gale, P. Hanks and D. Hindle (1991). Using Statistics in Lexical Analysis. In Zernik ed., 115-164.

Hoover, D. L. (2003). Another Perspective on Vocabulary Richness. Computers and the Humanities 37(2), 151-178.

Hunston, S. and G. Francis (1999). Pattern Grammar. A Corpus-driven Approach to the Lexical Grammar of English. Amsterdam: John Benjamins.

Mcenery, T. and A. Wilson (1996). Corpus Linguistics. Edinburgh: Edinburgh University Press.

McCrum, R., W. Cran and R. MacNeil. (1992). The Story of English. New York: Penguin.

Rayson, P., A. Wilson, T. McEnery, A. Hardie and S. Khoja, eds. (2001). Technical Papers. Volume 13. Special Issue. Proceedings of the Corpus Linguistics 2001 Conference.

Sánchez, A., ed. (1995). Cumbre. Corpus lingüístico del español contemporáneo. Fundamentos, metodología y aplicaciones. Madrid: Sociedad General Española de Librería.

Sánchez, A. and P. Cantos (1997). Predictability of Word Forms (Types) and Lemmas in Linguistic Corpora. A Case Study Based on the Analysis of the CUMBRE Corpus: An 8-Million-Word Corpus of Contemporary Spanish'. International Journal of Corpus Linguistics 2(2): 259-280.

Sánchez, A., and P. Cantos (1998). El ritmo incremental de palabras nuevas en los repertorios de textos. Estudio experimental y comparativo basado en dos corpus lingüísticos equivalentes de cuatro millones de palabras, de las lenguas inglesa y española y en cinco autores de ambas lenguas. ATLANTIS XIX(2): 205-223.

Sánchez, A., ed. (2001). Gran diccionario de uso del español actual. Madrid: Sociedad General Española de Librería.

Sinclair, J. (1991). Corpus, Concordance, Collocation. Oxford: Oxford University Press.

The New Oxford Dictionary of English (1998). Oxford: Oxford University Press.

Tuldava, J. (1995). Methods in Quantitative Linguistics. Trier: Wissenschaftlicher Verlag Trier.

Webster's Third New International Dictionary (2010). Springfield: Merriam Webster Inc.

Woods, A., P. Fletcher and A. Hughes (1986). Statistics in Language Studies. Cambridge: Cambridge University Press. 
Yang, D. H., P. Cantos, M. Song (2000). An Algorithm for Predicting the Relationship between Lemmas and Corpus Size. International Journal of the Electronics and Telecommunications Research Institute (ETRI) 22: 20-31.

Zernik, U. ed. (1991). Lexical Acquisition: Exploiting On-line Resources to Build a Lexicon. Hillsdale, NJ: Lawrence Erlbaum Associates.

Zipf, G. (1935). The Psycho-Biology of Language. Boston: Houghton Mifflin. 